SCIENCE CHINA
Technological Sciences

Special Topic: Biomedical Polymer Materials

- Review•
May 2022 Vol.65 No.5: 1000-1010

https://doi.org/10.1007/s11431-021-1962-x

\title{
Antibacterial surfaces: Strategies and applications
}

\author{
YANG XiaoMeng ${ }^{1}$, HOU JianWen ${ }^{1}$, TIAN Yuan ${ }^{2}$, ZHAO JingYa $^{1}$, SUN QiangQiang ${ }^{1 *} \&$ \\ ZHOU ShaoBing ${ }^{1 *}$ \\ ${ }^{1}$ Key Laboratory of Advanced Technologies of Materials, Ministry of Education, School of Materials Science and Engineering, \\ Southwest Jiaotong University, Chengdu 610031, China; \\ ${ }^{2}$ School of Life Science and Engineering, Southwest Jiaotong University, Chengdu 610031, China
}

Received September 21, 2021; accepted November 12, 2021; published online January 4, 2022

\begin{abstract}
Antibacterial surfaces are surfaces that can resist bacteria, relying on the nature of the material itself. It is significant for safe food and water, human health, and industrial equipment. Biofilm is the main form of bacterial contamination on the material surface. Preventing the formation of biofilm is an efficient way to develop antibacterial surfaces. The strategy for constructing the antibacterial surface is divided into bacteria repelling and bacteria killing based on the formation of the biofilm. Material surface wettability, adhesion, and steric hindrance determine bacteria repelling performance. Bacteria should be killed by surface chemistry or physical structures when they are attached to a material surface irreversibly. Killing approaches are usually in the light of the cell membrane of bacteria. This review summarizes the fabrication methods and applications of antibacterial surfaces from the view of the treatment of the material surfaces. We also present several crucial points for developing long-term stability, no drug resistance, broad-spectrum, and even programable antibacterial surfaces.
\end{abstract}

antibacterial surface, bacteria repelling, bacteria killing

Citation: Yang X M, Hou J W, Tian Y, et al. Antibacterial surfaces: Strategies and applications. Sci China Tech Sci, 2022, 65: 1000-1010, https://doi.org 10.1007/s11431-021-1962-x

\section{Introduction}

As the most numerous living organisms on earth, bacteria have a profound influence on human activities, ranging from industrial operations to human health [1,2]. Bacteria can be used for producing yogurt, wine, antibiotics and can be applied to other biotechnological fields [3-5]. However, the considerable problems caused by bacteria also present a big challenge. For example, bacteria threaten the quality and safety of food and water, leading to various human diseases. Bacteria exist not only in the bulk phase but also on surfaces that play an important role in their growth, proliferation, and spreading. In most cases, bacteria gather on the surface of different materials and generate biofilm [6]. Biofilm often

*Corresponding authors (email: qiangqsun@swjtu.edu.cn; shaobingzhou@swjtu.edu.cn) causes biological pollution in a variety of industries, including adhering to the inner wall of water pipelines resulting in poor water quality [7], adhering to the hull surface resulting in marine equipment corrosion, and increasing resistance and energy consumption [8,9]; biofilm formed on the surface of implanted biomaterials can cause serious harm to the human body, in terms of infection [10-13]. Thus, the development of an antibacterial surface is of significance to prevent the potential threats from bacteria in a range of industries and applications.

Traditional approaches for constructing antibacterial surfaces are usually based on the leaching of encapsulated biocides such as triclosan, yet these approaches can result in environmental pollution and bacterial resistance. Surface modification can endow materials with remarkable functionalities such as superwetting, anti-icing, anti-reflection, 
drag reduction, self-cleaning, and self-healing, using physical and chemical approaches [14]. Antibacterial surfaces can also be fabricated by the interdisciplinary of chemistry, physics, and materials science. Unlike the noxiousness of the previous bactericides, intrinsic antibacterial properties of modified surfaces are more environmentally friendly and can be adapted to various application situations by selecting the surface topography and chemical properties [15-18].

Biofilm is the primary form of surface bacterial contamination, which causes serious problems and can easily lead to drug resistance. It is difficult to remove biofilm completely by conventional sterilization methods [19]. The most efficient surface antibacterial method is to prevent the formation of biofilm. The process of biofilm formation can be divided into four stages including, the reversible contact stage, irreversible contact stage, colony formation stage, and biofilm maturation stage [20]. Based on the formational stages of biofilm on solid surfaces, antibacterial processes can be divided into bacterial repel-ling before attachment and bacterial killing after attachment.

It is difficult for bacteria to form biofilm on a repelling surface, as bacteria attachment is the first step of biofilm formation. Therefore, an important strategy to prevent biofilm formation is by limiting the initial adhesion of bacteria to solid surfaces. Bacteria repelling properties are dictated by surface roughness, hydrophobicity, electrostatic interactions, van der Waals forces, and steric hindrance [21]. Once bacteria are attached to the surface irreversibly, the remedial action is to kill them through chemical substances or inhibit them through physical structures. For example, bacteria can be killed by modified positive functional groups on the surface, since there are some anionic lipids on the phospholipid bilayer of the bacterial outer membrane (Figure 1). Surfaces treated with sharp microstructures also inhibit bacteria by puncturing cell membranes or limiting their activity. In this paper, we will review the antibacterial surface from the view of material surface modification, including physical topography, chemical molecules, and their synergism.

This review is divided into two main parts. The first part will introduce the antibacterial surface treatment strategies, whilst the second part concerns the application of developed antibacterial surfaces. The aim of this review is to provide newcomers to the field a reference compilation, background information and proper guidance in the design and preparation of novel antibacterial surfaces.

\section{Surface antibacterial strategies}

Bacteria, as a common form of life, is widely distributed in the environment. Bacteria come in various shapes such as coccus, bacillus, and spiral and their sizes range from 0.5 to
$50 \mu \mathrm{m}$. The structure of bacteria mainly consists of the cell walls, cell membranes, cytoplasm, and nucleoids. Based on the physiological characteristics of bacteria, researchers developed various surface antibacterial strategies. Antibacterial strategies can be broadly divided into bacterial repelling and killing, as shown in Figure 2. Repelling prevents bacteria from adhering to the surface, whilst killing refers to killing the bacteria that contact or come near to the surface. Both strategies rely on the prevention of bacterial reproduction to inhibit biofilm formation.

\subsection{Surface treatment strategies for bacterial repelling}

Surfaces that are bacterial repelling are capable of inhibiting the interaction between the material surface and surface bacterial proteins or proteins within the bacterial body. By processing the material surface with a micro-nano structure or adjusting the hydrophobicity of the surface by chemical methods, the surface can effectively reduce the initial attachment of bacteria and the formation of biofilm, so as to achieve an efficient antibacterial effect.

\subsubsection{Superhydrophobic surface for bacterial repelling} The superhydrophobic surface shows a water contact angle higher than $150^{\circ}$ and a small contact angle hysteresis less

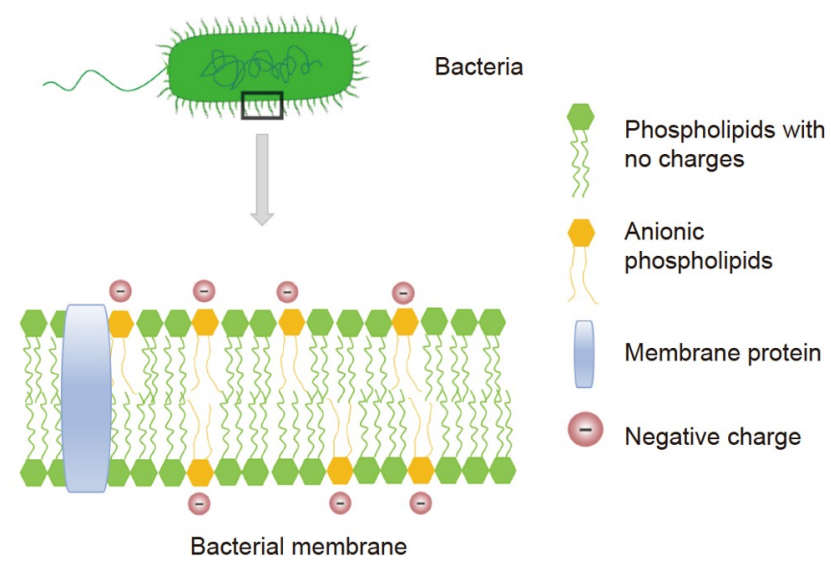

Figure 1 (Color online) Brief schematic diagram of the surface structure of the bacterial cell membrane. The phospholipid bilayer on the bacterial cell membrane contains anionic lipids, which make the bacterial surface negatively charged.

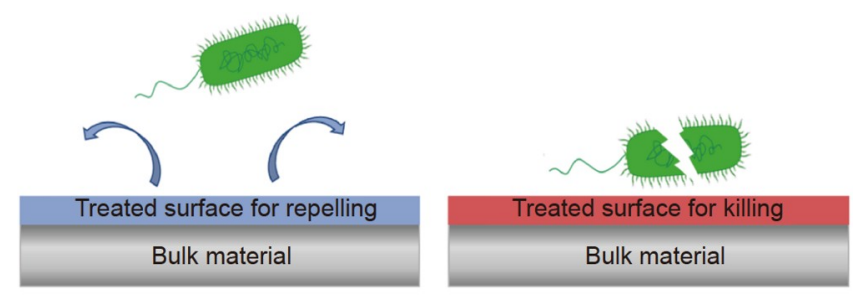

Figure 2 (Color online) Surface antibacterial strategies of repelling and killing. 
than $5^{\circ}$ due to its microstructure and low surface energy. The large size microstructure $(0.5-5 \mu \mathrm{m})$ on the superhydrophobic surface can effectively reduce the adhesion of bacteria, and at the same time, reduce the risk of colony formation [22,23]. Researchers have shown that when the microstructural pattern size on the surface is close to the size of the bacteria, the contact points provided for the bacteria will be reduced. The reduction of contact points makes the attachment of bacteria on the surface difficult, thus inhibiting the formation of biofilms effectively [24]. Researchers have proposed a mechanism that can further explain this (Figure 3) $[25,26]$. A layer of air bubbles forming between a superhydrophobic surface and liquid makes bacterial cells slide down with nano-scale bubbles. Because bacteria are unable to cross the air-water interface, eventually, they will accumulate at the tri-phase interface that provides the best shelter from water turbulence.

There are many superhydrophobic surfaces with selfcleaning abilities in nature, such as the lotus leaf, and the eyes of mosquitoes and flies. At present, many bioinspired approaches to fabricate superhydrophobic surfaces have been developed, such as surface deposition, polymer surface solvent treatment, and chemical or physical etching [27].

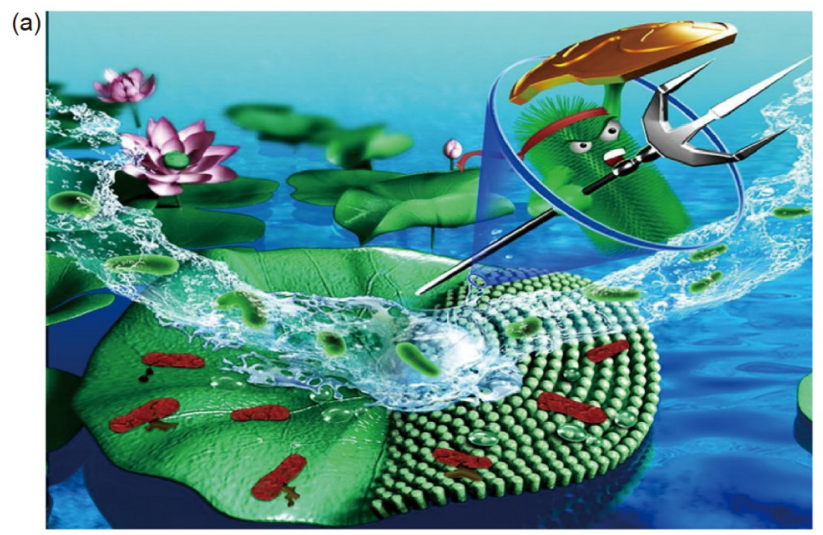

(b)

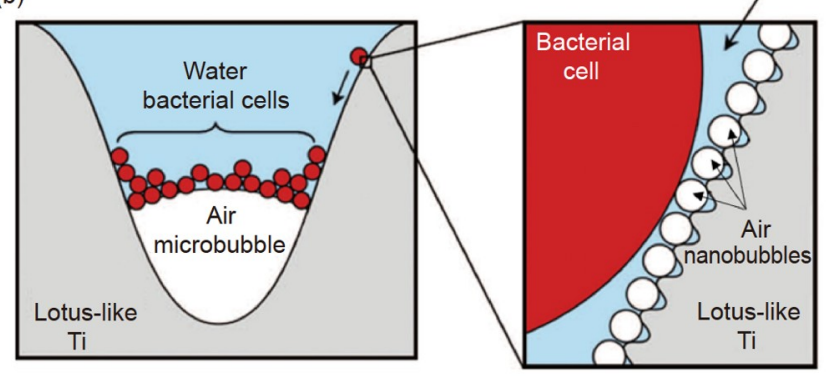

Figure 3 (Color online) Superhydrophobic surfaces with antibacterial properties. (a) The superhydrophobic lotus leaf for bacterial repelling [26]; (b) bacteria accumulate on the tri-phase interface of the Ti surface with similar micro-nano structures like on a lotus leaf. Bacteria slide down through the nano-scale bubbles between the sidewall of the nanocolumn and water, eventually becoming trapped and accumulating in the nanotopographyical gap, which provides the best shelter from water turbulence [25].

\subsubsection{Superhydrophilic surfaces for bacterial repelling}

Differing from the bacterial repelling mechanism of the superhydrophobic surfaces using micro-structures, superhydrophilic surfaces modified with zwitterionic polymers also exhibit excellent anti-fouling performance. The reason for superhydrophilic surfaces being bacterial repelling is because hydrophilic molecules can induce hydration and form a layer of water on the surface. The hydration layer endows the surface with excellent resistance to non-specific proteins and microorganisms, such as bacteria and plankton in the ocean $[8,9]$.

One of the approaches of preparing superhydrophilic surfaces is through the grafting process, which is divided into "grafting to" and "grafting from" [28]. "Grafting to" means directly linking the hydrophilic polymer onto the surface by covalent bonds, while "grafting from" means that the monomer is grafted first, and then polymerization is initiated on the surface. At present, the methods used to graft highly hydrophilic polymers to the surface of materials to achieve bacterial repelling properties are mainly through surfaceinitiated active/controllable free radical polymerization reactions such as reversible addition-fragmentation chain transfer polymerization (RAFT) and atom transfer free radical polymerization (ATRP) [29,30].

\subsubsection{Slippery surfaces for bacterial repelling}

The micro-texture on the surface of Nepenthes can lock in the intermediate liquid, turning itself into an efficient repellent surface. Inspired by Nepenthes, Wong et al. [31] designed a porous surface infused with a lubricating liquid. Introducing a micro-nano-scale rough structure and allowing the lubricating fluid to diffuse on the surface through capillary action can make the surface have excellent antiadhesion properties. Due to the strong van der Waals attraction between the lubricating liquid and the structured surface, the lubricating liquid can be firmly adsorbed in the rough structure on the surface. As a lubricant injected into the surface, it can effectively prevent the adhesion of bacteria.

Researchers have designed various slippery antibacterial surfaces. Doll et al. [32] used commercial femtosecond laser systems to achieve hierarchical micro-and-nano-sized spikes, and then dip-coated perfluoropolyether lubricants with different viscosities on the prepared samples to obtain a liquid-infused surface. The study found that intermediate viscosity perfluoropolyether lubricants exhibited the strongest anti-bacterial adhesion effect and can persistently and effectively inhibit the formation of biofilms. Li et al. [33] grafted a layer of polybutyl methacrylate-co-ethylene dimethacrylate (BMA-EDMA) with the porous structure on the glass surface through UV-initiated radical polymerization (Figure 4). By smearing excessive amounts of perfluoropolyether on the inclined prepared surface, and al- 

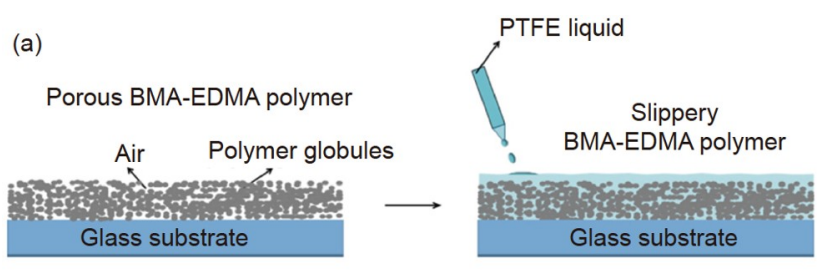

(b)

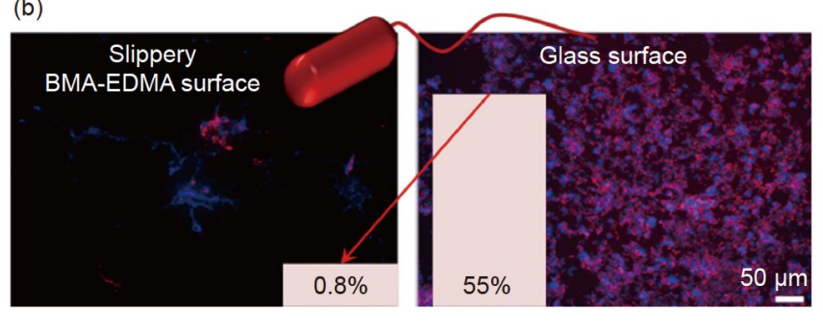

Figure 4 (Color online) Slippery antibacterial surface. (a) Schematic illustration of the fabrication of the slippery BMA-EDMA surface by infusing the porous polymer with a perfluoropolyether fluid; (b) the antibacterial properties of this slippery surface [33].

lowing the excess to flow out naturally, a liquid-infused antibacterial slippery surface is obtained. This surface exhibits excellent anti-bacterial adhesion and anti-biofilm formation properties in bacteria solutions of low concentration media. However, it does not perform well in bacterial solutions with a high concentration media.

\subsection{Surface treatment strategies to kill bacteria}

Once the surface fails to repel bacteria, the next option is to kill them through modified surface properties, to realize the surface antibacterial function. A variety of approaches have been used to construct bactericidal surfaces. The representative ones include covering the surface using metal nanoparticles, cationic polymers, antimicrobial peptides, and structuring the surface on a micro-nano scale. The next part of this review will summarize the disinfection principles and treatment processes of different bactericidal surfaces.

\subsubsection{Coating the surface with metal nanoparticles}

Silver nanoparticles are currently one of the most widely used bactericidal agents with spectral antibacterial effects. The bactericidal properties of silver nanoparticles come from the direct interaction between the nanoparticles and the silver ions released from silver. When bacteria attach to silver nanoparticles, the silver nanoparticles will induce local membrane perforation. Nanoparticles can be internalized through the broken membrane, leading to further damage to the bacteria. $\mathrm{Ag}^{+}$released from silver nanoparticles is the crucial factor in the antibacterial process. The bactericidal ability of silver nanoparticles is also derived from the induction of $\mathrm{Ag}^{+}$-related reactive oxygen species [34]. Studies have shown the $\mathrm{Ag}^{+}$generation process as
$4 \mathrm{Ag}(0)+\mathrm{O}_{2} \rightarrow 2 \mathrm{Ag}_{2} \mathrm{O}$

$$
2 \mathrm{Ag}_{2} \mathrm{O}+4 \mathrm{H}^{+} \rightarrow 4 \mathrm{Ag}^{+}+2 \mathrm{H}_{2} \mathrm{O}
$$

The silver nanoparticle is used in surface antibacterial treatments in a variety of ways, such as physical or chemical deposition and magnetron sputtering $[35,36]$. The nanoparticle coating allows $\mathrm{Ag}^{+}$to be released from the surface over time.

$\mathrm{Cu}$ also exhibits excellent antibacterial properties as it can be quickly oxidized to $\mathrm{Cu}^{2+}$ ions in air or water media, which can interfere with the oxidation of proteins, cause DNA and RNA molecule cleavage and generate reactive hydroxyl radicals which break down the membranes of bacteria as a result of lipid peroxidation $[37,38]$. There have been many studies on the processing of copper into nanoparticles, and loading them on the surface in various ways for antibacterial applications [39,40]. Cometa et al. [39] designed a copper nanoparticle, encapsulated, hydrogel antibacterial coating that can be firmly attached to the surface of stainless steel. The stainless steel surface shows excellent antibacterial properties after being treated. Benetti et al. [40] adopted supersonic cluster beam deposition technology to condense $\mathrm{Ag}, \mathrm{Cu}$, and $\mathrm{Mg}$ into nanoparticles, which are deposited and adhere to surfaces of the soda-lime glass substrate. The prepared surface shows excellent broad-spectrum antibacterial activity.

\subsubsection{Grafting the surface with cationic polymers}

Considering the negative charge on the bacterial cell membranes, there are many reports regarding the use of cationic polymers to achieve better surface bactericidal effects. Quaternary ammonium salt is the most widely used cationic antibacterial polymer. Two antibacterial mechanisms are proposed. One is that long-chain cationic polymers can pierce the cell membrane of bacteria like a needle piercing a balloon, and the other is that the proximity of the cationic chain will cause the anion in the bacterial cell membrane to dissociate, leading to membrane breakdown and death of the bacteria [41]. Cationic polymers can construct a contactkilling bactericidal surface through grafting, coupling, or covalently bonding a cationic polymer layer on the material surface, making the material obtain a stable contact sterilization ability. Chen et al. [42] grafted poly $\{1,3-b i s(\mathrm{~N}, \mathrm{~N}-$ dimethyl-N-octyl ammonium)-2-propyl acrylate dibromide (PAGC8) with a dual cationic group and dual hydrophobic tail onto the silicon wafer by surface-initiated atom transfer radical polymerization (SI-ATRP). A cationic polymer brush layer with ultra-high cationic surface charge density is formed on the silicon wafer. Compared with surface modifications with only a single cationic group $\left(\mathrm{PASC}_{1}\right)$, or a single cationic group with a single hydrophobic tail $\left(\mathrm{PASC}_{8}\right)$, this polymer can more effectively adsorb bacteria and insert the phospholipid bilayer of the 
bacterial cell membrane to kill the bacteria (Figure 5 [42]). Liu et al. [43] prepared a phosphonate/quaternary amine block polymer. The phosphate group at the tail allows this cationic polymer to form a strong covalent bond with the metal substrate, while the cationic chain at the head exerts the antimicrobial effects. By varying the repeated unit number of cationic segments, it was found that polymers with longer cationic segments have better bactericidal abilities.

\subsubsection{Fabricating bionic antibacterial surfaces with a nano-scale structure}

The surfaces of certain organisms in nature have natural bactericidal functions, such as insect wings (cicada/dragonfly wings), moth eyes, and gecko skin. For some, the antibacterial effect is achieved by killing the attached bacteria on their surface. For example, the surface of cicada wings has nano-scale, three-dimensional patterns, which are smaller than the size of bacteria, as shown in Figure $6[44,45]$. When bacterial cells are adsorbed onto them, the cell membrane will be stretched by the nano-pillar [46].

If $T_{0}$ is set to be the strain of the vertices, then the strain at the dividing line $T_{r_{0}}$ can be regarded as [47]

$T_{r_{0}}=T_{0}-\frac{\lambda R^{2}}{2 H} \sqrt{1+\left(\frac{2 H}{R^{2}} r_{0}\right)^{2}}$.

If the degree of stretching is large enough, the cell will rupture, thus achieving the bactericidal effect. This kind of surface can kill bacteria, yet dead bacteria accumulate on the surface and are not easily removed. Various surface processing techniques have been used to prepare biomimetic micro/nano-scale structures, including reactive ion beam etching [48], plasma etching [49], microwave plasma chemical vapor deposition [48], and nanoimprint lithography [50].

Ge et al. [51] prepared a bionic cicada wing with a nanostructured and fluorinated hydroxyapatite surface using the electrochemical method. Through tuning the working parameters of the electrochemical method (including potential, current density, and duration), it is possible to obtain nanostructures with a precise, large size for effective surface antibacterial effect. Polyetherketone is a material widely used in orthopedic surgeries. Ye et al. [52] penetrated the polyether ketone into a porous anodic aluminum oxide template to obtain the polyether ketone sheet with bionic cicada wing nanostructures.

\section{Surface antibacterial applications}

Since biological materials make contact with the internal or external environment of the human body, it is of great significance to endow biological materials with antibacterial properties. The antibacterial surface ensures safety towards

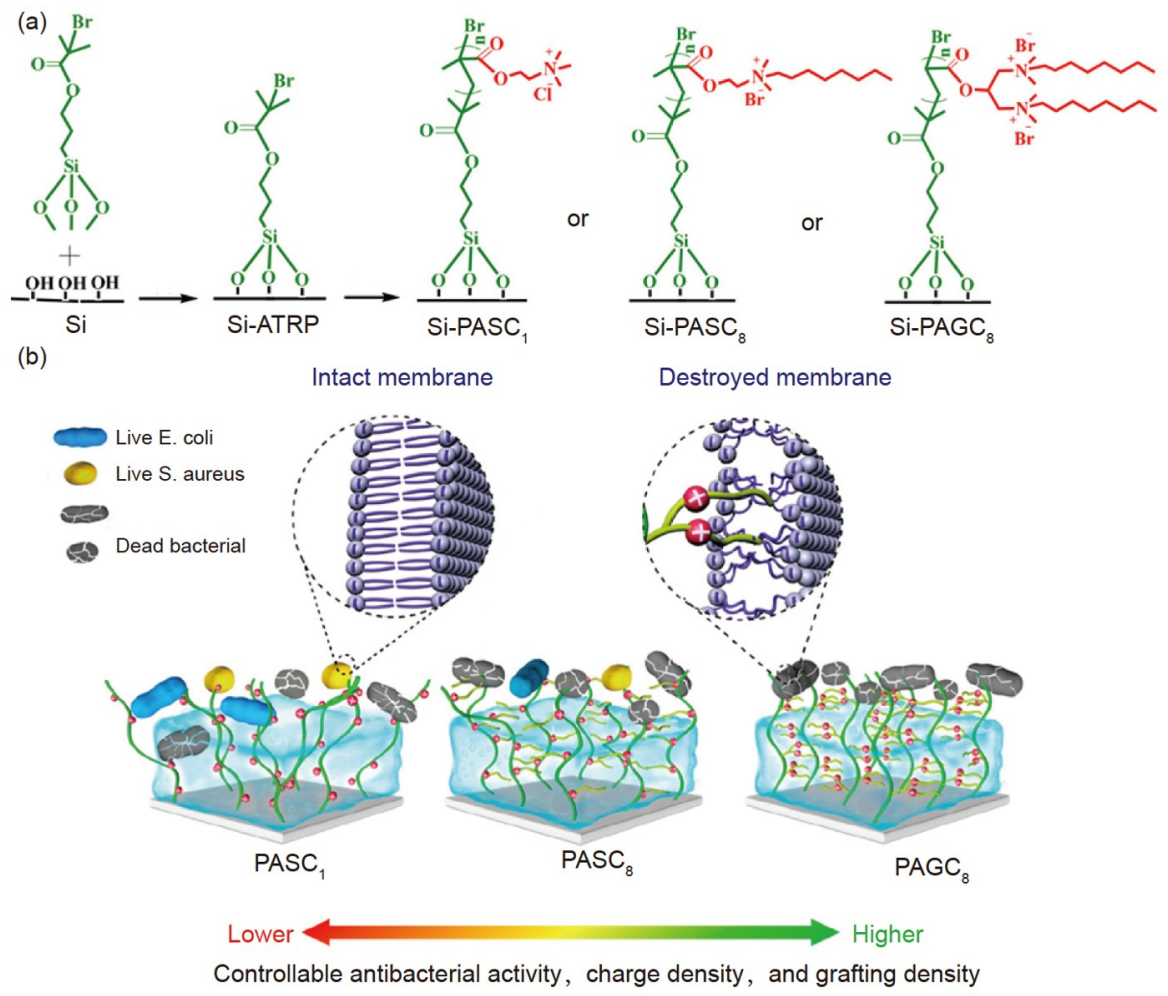

Figure 5 (Color online) An antibacterial surface grafted with a cationic polymer. (a) Synthetic routes of different polymer brushes; (b) schematic illustration of antibacterial mechanisms and antibacterial efficiency changing with cationic polymer brush density [42]. 
(a)

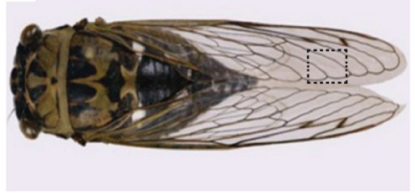

清

(b)
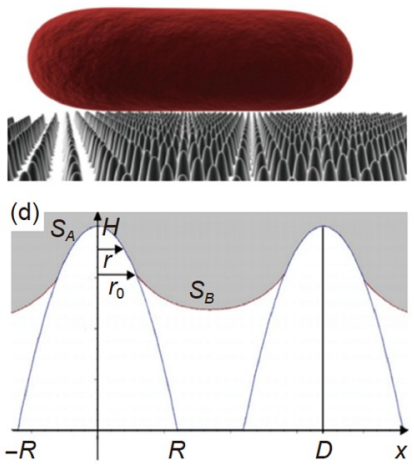

Figure 6 (Color online) Cicada wings with the bactericidal ability and their mechanism. (a) Photo of a cicada [44]; (b) schematic representation of a bacteria adsorbed onto the nanopillars of a cicada wing; (c) bacteria collapse onto the surface due to the cell membrane being stretched between the nanopillars [45]; (d) a schematic diagram of the side-elevation of the bacterial membrane adsorbed on two neighboring nanoridges, where $H$ is the height of the nano ridge, $2 R$ is the bottom width of the nanoridge, $S_{A}$ is the contact area of the bacterial membrane covering the nano ridge, and $S_{B}$ is the suspended membrane area. $r_{0}$ is the distance from the dividing line to the $x$-axis, and $D$ is the distance between two neighboring nanopillars.

the biological material and prevents functional failure when acting upon the human body. Many studies have been conducted based on the surface modification of various implant materials in order that they possess antibacterial properties. In addition, antibacterial modification of fabrics is desirable for people's daily lives with the awareness of the improvement it can bring to hygiene and health. Next, we will introduce the applications of antibacterial surfaces in orthopedic implants, medical catheters, and fabrics.

\subsection{Orthopedic implants}

The embedding process of orthopedic implants into the human body takes place in an air environment, meaning there is a bacterial infection risk. If bacteria that have the ability to form a biofilm are introduced by the implant itself or the internal environment during the operation process, it will lead to serious postoperative complications and even failure of the implant function [53,54]. Infections caused by implanted devices seriously endanger the patient's health, since implant-related infection is difficult to eliminate through normal antibiotic therapy and often requires surgical intervention with secondary damage to the patient [55]. In order to prevent bacterial adhesion and proliferation on the implant's surface and inhibit the formation of biofilm, antibacterial modification is necessary in addition to disinfection.

As shown in Figure 7 [56,57], the antibacterial modification of orthopedic implants can also be divided into bacterial repelling and killing, in addition to other specific properties. Researchers have designed various surfaces for orthopedic (a)

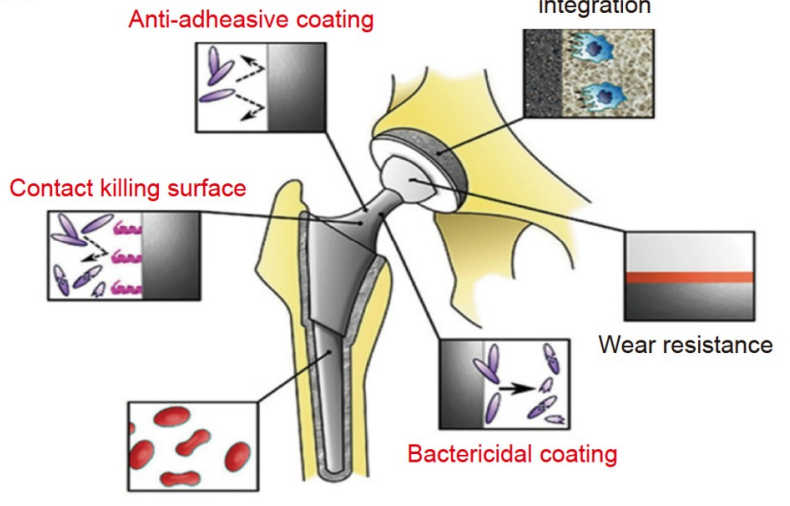

(b)

$$
\text { Biocompatibility }
$$

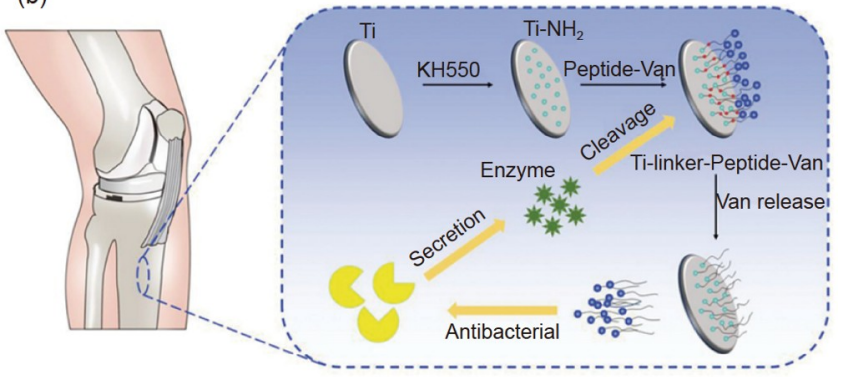

Figure 7 (Color online) Applications in antibacterial orthopedic implants. (a) Antibacterial properties and other necessary characteristics on the surface of an orthopedic implant [56]; (b) the design of a bacterial infection-responsive antibacterial material used in an orthopedic implant [57].

implants to inhibit the formation of biofilms [58-60], such as anti-adhesion surfaces, responsive biocides-containing coating. Physical and chemical treatments are a simple and effective approach for the surface preparation of antibacterial implants. For example, increasing the wettability of the titanium alloy surface by ultraviolet radiation and transforming the amorphous surface structure into anatase titanium oxide by anodic oxidation, can conveniently and efficiently reduce the adhesion of bacteria on the material surface $[61,62]$. The high-density hydrophilic polymer coating on the implant surface can also effectively reduce the adhesion of bacteria by forming a tightly bonded water layer on the surface [63]. In addition, the slowly released biocides on the implant surface can effectively inhibit the formation of biofilms $[64,65] . \mathrm{Mg}$ is widely used in cardiovascular and orthopedic implants because of its good mechanical strength and biodegradability [66]. The antibacterial agent carboxymethyl chitosan can be immobilized on alkali-treated $\mathrm{Mg}$ alloy to give Mg implants good antibacterial properties [67].

\subsection{Medical catheters}

As one of the most commonly used medical devices in hospitals, catheter-related infection is a serious threat to the patient's health [68]. Urinary tract infections caused by ca- 
theters are responsible for approximately $80 \%$ of global nosocomial infections [69]. It was reported to be of 6.8 infections per 1000 central line days in Asia, and the crude mortality rate due to catheter infection in ICUs is up to $25 \%$ [70]. By monitoring patients suspected of catheter-related infection in tertiary hospitals in China, researchers found that $19.2 \%$ of them were eventually diagnosed, and $17.4 \%$ died within 30 days [71].

Studies have shown that indwelling catheter-related infections caused by bacterial biofilms account for most medical device infections. Among them, catheter-related urinary tract infections and bloodstream infections are the most common [72]. Antibacterial properties of medical catheters mainly include antibacterial adhesion and sterilization. At present, the construction of antibacterial catheter surfaces is mainly achieved via three methods: coating, grafting, and bulk modification [73-76]. The coating is mainly achieved by physical modification, that is, the antibacterial agent is physically adsorbed to the polymer surface through non-covalent bonds, including electrostatic interaction, van der Waals force, hydrophobic interaction, multidentate ligands, and $\pi-\pi$ stacking $[77,78]$. Based on these interactions, some technologies have been developed to build coatings on the surface, including layer-by-layer self-assembly and spin coating. The redox polymerization reaction between methacryloyl ethyl sulfobetaine (SB) and ferrous gluconate grafts the inner salt to the surface of the peripheral venous catheter, which can significantly reduce bacteria adhesion and biofilm formation in vivo and in vitro (Figure 8) [79]. Amino cellulose nanospheres and polyanionic hyaluronic acid can build an antibacterial coat through layer by layer self-assembly on the 3-aminopropyltriethoxysilane pretreated silicon resin catheter surface, the coating will gradually decompose and release the antibacterial agent when bacteria are present near the surface [80]. Yu et al. $[81,73]$ constructed an antibacterial coating on the surface and lumen of catheters by van der Waals force, using poly- electrolyte-surfactant complexes. The coatings can be prepared on the surface of various shapes and material types and have broad-spectrum antibacterial properties and good biocompatibility. Experiments show that catheters prepared by this method have anti-bacterial colonization abilities and also show long-lasting antibacterial properties in vivo.

\subsection{Fabrics}

With today's requirements for an improved quality of life and health, antibacterial fabrics have gradually attracted more attention, and many treatment methods for creating them have been derived [82-85]. Excellent antibacterial fabrics should have specific properties, including stability and low pollution to aquatic ecosystems after multiple washings. Cotton fiber containing silver nanoparticles, with excellent leaching resistance, is prepared using an in-situ synthesis method, which can effectively prevent water pollution caused by traditional silver-containing fabrics (Figure 9(a)) [84]. By sequentially immersing cotton fibers in sodium hydroxide solution and a mixed solution of ammonium hydroxide and silver nitrate, the microfibrillar structure of the fiber firstly becomes swollen under alkaline conditions, which provides silver nanoparticles with inner channels. A complex $\left[\mathrm{Ag}\left(\mathrm{NH}_{3}\right)_{2}\right]$ ion is formed in the mixed solution, which can combine with cellulose oxyanions and then be reduced to silver. After nucleation growth, silver nanoparticles can be synthesized in situ in cotton fiber. This processing method guarantees that the treated cotton fiber still has a high antibacterial effect even after repeated washing, keeping the killing rate of Pseudomonas aeruginosa and Staphylococcus aureus above $99 \%$.

Due to the COVID-19 pandemic, researchers are also working on highly-effective protective masks, for example, a sun-induced antibacterial/antiviral mask (Figure 9(b)) [85]. The bactericidal ability is derived from the photosensitizer combined with the short cationic chain on the cotton fiber of

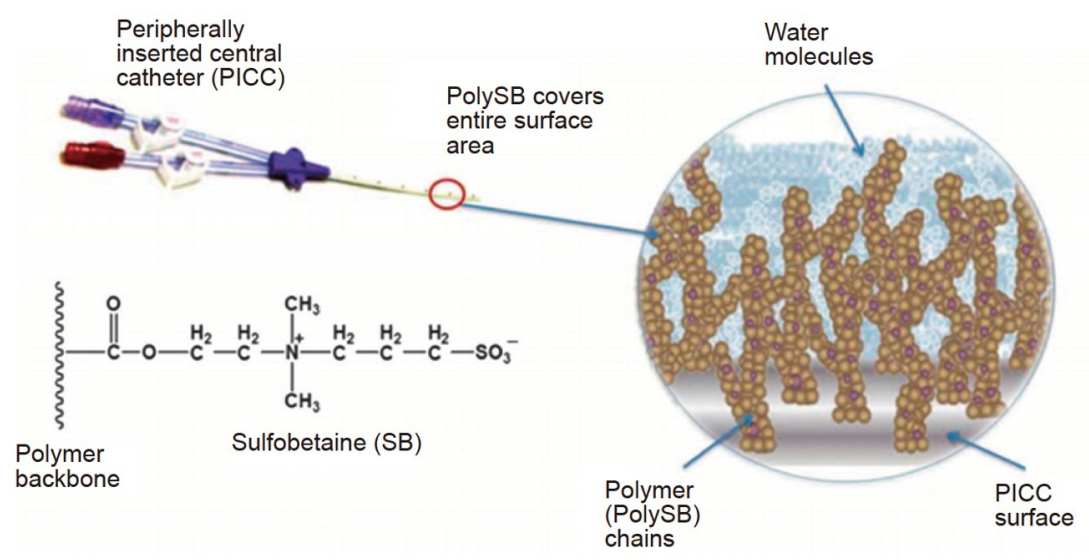

Figure 8 (Color online) Strategy for constructing an antibacterial surface on the medical catheter. PolySB is bound to the surface of the PICC to form a conformal polymer surface. The zwitterionic polySB modification coordinates both free and bind water molecules to create a hydrophilic antibacterial surface [79]. 
the mask. The photosensitizer combines with a polycation short chain through strong electrostatic interactions. It can produce a large amount of reactive oxygen species under sunlight, which have strong microbial killing abilities and hence offer good protection.

\section{Summary and perspectives}

Antibacterial surfaces are a way of preventing bacterial contamination without the use of antibiotics. This review has summarized the various surface antibacterial strategies, divided into bacteria-repelling and bacteria-killing and their applications, as summarized in Table 1. Textured and chemically modified surfaces for antibiosis have been developed. However, novel approaches and more breakthroughs for designing stable and versatile antibacterial surfaces are essential in order to adapt to different materials (including polymers, textiles, semiconductors, and metals) and application scenarios (such as food packaging, biomedical devices, industrial pipelines, and shipbuilding).

Current research surrounding antibacterial surfaces has provided remarkable development, yet approaches with long-term stability, no drug resistance, broad-spectrum, and even programmability still need to be explored. The surface design should be targeted to the characteristics of bacteria walls, enabling the antibacterial surface to be selective for bacteria. Specific properties on the biological cells such as bacteria structure, type, adhesion force, and featured proteins should be considered and explored further. The antibacterial surface is also expected to develop towards multifunctionality through combining self-cleaning, drag-reduc- (a)

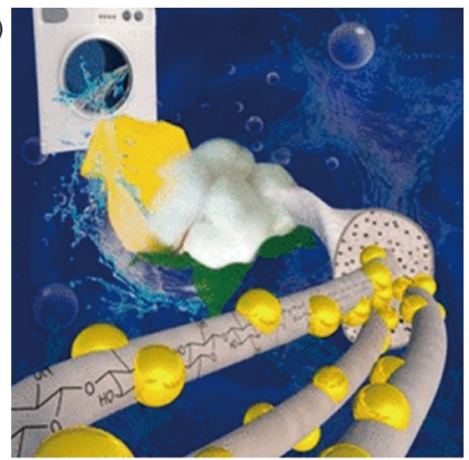

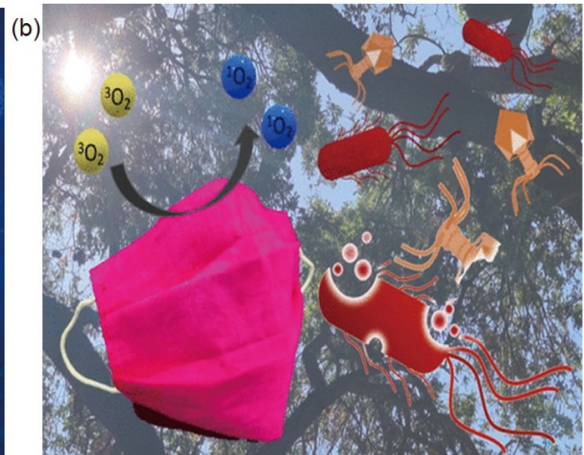

Figure 9 (Color online) Antibacterial fabrics. (a) A fabric capable of keeping durable antibacterial functions with silver ions after repeated washing [84]; (b) a photo-responsive antibacterial mask [85].

Table 1 Summary of different antibacterial strategies

\begin{tabular}{|c|c|c|c|c|c|}
\hline $\begin{array}{l}\text { Antibacterial } \\
\text { strategies }\end{array}$ & Approaches & Principle & Fabrication methods & Efficiency evaluation & Applications \\
\hline \multirow{3}{*}{$\begin{array}{l}\text { Bacterial } \\
\text { repelling }\end{array}$} & $\begin{array}{l}\text { Superhydrophobic } \\
\text { surface }\end{array}$ & $\begin{array}{l}\text { Microstructural size ef- } \\
\text { fect and air bubble layer }\end{array}$ & $\begin{array}{c}\text { Surface deposition, polymer surface } \\
\text { solvent treatment, and chemical or } \\
\text { physical etching [86-88] }\end{array}$ & $\begin{array}{l}\text { Long-term anti-bacteria } \\
\text { adhesion }\end{array}$ & $\begin{array}{l}\text { Commune facilities } \\
\text { and industrial } \\
\text { equipment }\end{array}$ \\
\hline & $\begin{array}{l}\text { Superhydrophilic } \\
\text { polymer layer }\end{array}$ & $\begin{array}{l}\text { Hydration forms a layer } \\
\text { of water }\end{array}$ & $\begin{array}{c}\text { Chemical grafting }[29,30,89] \text {, surface } \\
\text { separation technology }[90] \text {, biomi- } \\
\text { metic adhesion }[91,92]\end{array}$ & $\begin{array}{l}\text { Resistant to bacteria adhesion } \\
\text { and biofilm formation }\end{array}$ & $\begin{array}{l}\text { Hospital equipment } \\
\text { and medical catheter }\end{array}$ \\
\hline & Slippery surface & $\begin{array}{l}\text { Prevent the adhesion of } \\
\text { bacteria }\end{array}$ & $\begin{array}{c}\text { Graft polymer layer with porous } \\
\text { structure and dip-coat the lubricating } \\
\text { liquid }[32,93]\end{array}$ & $\begin{array}{l}\text { Long-term antibacterial ability. } \\
\text { It can effectively inhibit the } \\
\text { adhesion of bacteria. }\end{array}$ & Marine equipment \\
\hline \multirow{4}{*}{$\begin{array}{l}\text { Bacterial } \\
\text { killing }\end{array}$} & Metal nanoparticles & $\begin{array}{l}\text { Damage the structure } \\
\text { of the bacteria and } \\
\text { the bacteria's normal } \\
\text { function }\end{array}$ & $\begin{array}{c}\text { Deposition by liquid flame spraying or } \\
\text { magnetron sputtering }[35,36] \text {, super- } \\
\text { sonic cluster beam deposition tech- } \\
\text { nology }[40]\end{array}$ & $\begin{array}{l}\text { Low concentration of } \mathrm{Ag}^{+} \text {ion } \\
\text { is sufficient to effectively kill } \\
\text { bacteria }\end{array}$ & $\begin{array}{l}\text { Medical implants, } \\
\text { face mask, fabrics }\end{array}$ \\
\hline & Cationic polymer & $\begin{array}{l}\text { Destroy membrane } \\
\text { structure through elec- } \\
\text { trostatic interaction and } \\
\text { physical piercing }\end{array}$ & $\begin{array}{l}\text { Grafting cationic polymers using } \\
\text { ATRP or RAFT }[42,43]\end{array}$ & $\begin{array}{c}\text { Longer cationic polymer segment } \\
\text { and higher cation density give } \\
\text { material stronger antibacterial } \\
\text { ability }\end{array}$ & Medical implants \\
\hline & $\begin{array}{c}\text { Responsive } \\
\text { bactericidal drugs }\end{array}$ & $\begin{array}{l}\text { Destroy bacterial cell } \\
\text { membrane and inhibit } \\
\text { the development of drug } \\
\text { resistance }\end{array}$ & $\begin{array}{l}\text { Covalently bond or deposit antibiotic } \\
\text { with the sensitive agent on the surface } \\
{[56,94-96]}\end{array}$ & $\begin{array}{l}\text { Prevent the development of drug } \\
\text { resistance, and the sterilization } \\
\text { efficiency can reach } 100 \%\end{array}$ & \\
\hline & $\begin{array}{l}\text { Nano-scale micro- } \\
\text { structure }\end{array}$ & $\begin{array}{l}\text { Stretch and rupture } \\
\text { the bacteria in the } \\
\text { nanopillar area }\end{array}$ & $\begin{array}{c}\text { Biological template method [97], } \\
\text { electrochemical method [51], micro- } \\
\text { wave plasma chemical deposition [48], } \\
\text { nanoimprint lithography [50] }\end{array}$ & $\begin{array}{l}\text { The killing efficiency is often } \\
\text { below } 50 \% \text {, and the sharper and } \\
\text { smaller micro/nano-structure has } \\
\text { stronger bactericidal performance }\end{array}$ & $\begin{array}{l}\text { Commune facilities } \\
\text { and industrial } \\
\text { equipment }\end{array}$ \\
\hline
\end{tabular}


tion properties, based on the usage scenarios. An adjustable and programmable antibacterial surface benefits customizable applications. Electric properties can be further utilized for developing novel antibacterial surfaces. Hydrophobic surfaces with dielectric properties are negatively charged by contact with water or another surface, and thus this has the potential to be exploited as a bacteria-repelling surface because of the negative surface charge on bacteria. Dielectric materials are divided into negative and positive, based on their electric properties after contact electrification. Negative materials are also a good choice for bacteria-repelling surfaces, whilst positive materials have bactericidal abilities by combining or discharging with the negative bacterial surface. The external electric field can be applied on metal to realize the antibacterial surface. The electrostatic field is real-time controlled by tribology or power source so that it can be regarded as a universal and programmable approach. This new approach can avoid defects associated with an easily damaged surface coating as a result of its mechanical or chemical instability.

This work was supported by the National Natural Science Foundation of China (Grant No. 22105161), the Fundamental Research Funds for the Central Universities (Grant No. 2682021CX104), and the Sichuan Science and Technology Program (Grant Nos. 2020 YFSY0017 and 2020JDRC0051).

1 Singh B K. Organophosphorus-degrading bacteria: Ecology and industrial applications. Nat Rev Microbiol, 2009, 7: 156-164

2 Teusink B, Smid E J. Modelling strategies for the industrial exploitation of lactic acid bacteria. Nat Rev Microbiol, 2006, 4: 46-56

3 Dantas G, Sommer M O A, Oluwasegun R D, et al. Bacteria subsisting on antibiotics. Science, 2008, 320: 100-103

4 Kok C R, Hutkins R. Yogurt and other fermented foods as sources of health-promoting bacteria. Nutr Rev, 2018, 76: 4-15

5 Olaimat A N, Shahbaz H M, Fatima N, et al. Food safety during and after the era of COVID-19 pandemic. Front Microbiol, 2020, 11: 1854

6 Hong S H, Gorce J B, Punzmann H, et al. Surface waves control bacterial attachment and formation of biofilms in thin layers. Sci Adv, 2020, 6: eaaz9386

7 Hemdan B A, Azab El-Liethy M, El-Taweel G E. The destruction of Escherichia coli adhered to pipe surfaces in a model drinking water distribution system via various antibiofilm agents. Water Environ Res, 2020, 92: 2155-2167

8 Li Y, Ning C. Latest research progress of marine microbiological corrosion and bio-fouling, and new approaches of marine anti-corrosion and anti-fouling. Bioactive Mater, 2019, 4: 189-195

9 Salta M, Wharton J A, Blache Y, et al. Marine biofilms on artificial surfaces: Structure and dynamics. Environ Microbiol, 2013, 15: 28792893

10 Amin Yavari S, Castenmiller S M, van Strijp J A G, et al. Combating implant infections: Shifting focus from bacteria to host. Adv Mater, 2020, 32: 2002962

11 Arciola C R, Campoccia D, Montanaro L. Implant infections: Adhesion, biofilm formation and immune evasion. Nat Rev Microbiol, 2018, 16: 397-409

12 Campoccia D, Montanaro L, Arciola C R. A review of the clinical implications of anti-infective biomaterials and infection-resistant surfaces. Biomaterials, 2013, 34: 8018-8029

13 Wang C, Zhao W, Cao B, et al. Biofilm-responsive polymeric nano- particles with self-adaptive deep penetration for in vivo photothermal treatment of implant infection. Chem Mater, 2020, 32: 7725-7738

14 Liu K, Tian Y, Jiang L. Bio-inspired superoleophobic and smart materials: Design, fabrication, and application. Prog Mater Sci, 2013, 58: 503-564

15 Chang Y R, Weeks E R, Ducker W A. Surface topography hinders bacterial surface motility. ACS Appl Mater Interfaces, 2018, 10: 9225-9234

16 Epstein A K, Hochbaum A I, Kim P, et al. Control of bacterial biofilm growth on surfaces by nanostructural mechanics and geometry. Nanotechnology, 2011, 22: 494007

17 Epstein A K, Wong T S, Belisle R A, et al. Liquid-infused structured surfaces with exceptional anti-biofouling performance. Proc Natl Acad Sci USA, 2012, 109: 13182-13187

18 Natalio F, André R, Hartog A F, et al. Vanadium pentoxide nanoparticles mimic vanadium haloperoxidases and thwart biofilm formation. Nat Nanotech, 2012, 7: 530-535

19 Paula A J, Hwang G, Koo H. Dynamics of bacterial population growth in biofilms resemble spatial and structural aspects of urbanization. Nat Commun, 2020, 11: 1-4

20 Renner L D, Weibel D B. Physicochemical regulation of biofilm formation. MRS Bull, 2011, 36: 347-355

21 Donlan R M, Costerton J W. Biofilms: Survival mechanisms of clinically relevant microorganisms. Clin Microbiol Rev, 2002, 15: 167-193

22 Zwahr C, Helbig R, Werner C, et al. Fabrication of multifunctional titanium surfaces by producing hierarchical surface patterns using laser based ablation methods. Sci Rep, 2019, 9: 6721

23 Epperlein N, Menzel F, Schwibbert K, et al. Influence of femtosecond laser produced nanostructures on biofilm growth on steel. Appl Surf Sci, 2017, 418: 420-424

24 Chang S, Chen X, Jiang S, et al. Using micro-patterned surfaces to inhibit settlement and biofilm formation by Bacillus subtilis. Can J Microbiol, 2017, 63: 608-620

25 Truong V K, Webb H K, Fadeeva E, et al. Air-directed attachment of coccoid bacteria to the surface of superhydrophobic lotus-like titanium. Biofouling, 2012, 28: 539-550

26 Jiang R, Hao L, Song L, et al. Lotus-leaf-inspired hierarchical structured surface with non-fouling and mechanical bactericidal performances. Chem Eng J, 2020, 398: 125609

27 Xu S, Wang Q, Wang N. Chemical fabrication strategies for achieving bioinspired superhydrophobic surfaces with micro and nanostructures: A review. Adv Eng Mater, 2021, 23: 2001083

28 Krishnamoorthy M, Hakobyan S, Ramstedt M, et al. Surface-initiated polymer brushes in the biomedical field: Applications in membrane science, biosensing, cell culture, regenerative medicine and antibacterial coatings. Chem Rev, 2014, 114: 10976-11026

29 Li M, Liu X, Liu N, et al. Effect of surface wettability on the antibacterial activity of nanocellulose-based material with quaternary ammonium groups. Colloid Surfs A-Physicochem Eng Aspects, 2018, 554: $122-128$

$30 \mathrm{Xu}$ X, Huang X, Chang Y, et al. Antifouling surfaces enabled by surface grafting of highly hydrophilic sulfoxide polymer brushes. Biomacromolecules, 2021, 22: 330-339

31 Wong T S, Kang S H, Tang S K Y, et al. Bioinspired self-repairing slippery surfaces with pressure-stable omniphobicity. Nature, 2011, 477: 443-447

32 Doll K, Fadeeva E, Schaeske J, et al. Development of laser-structured liquid-infused titanium with strong biofilm-repellent properties. ACS Appl Mater Interfaces, 2017, 9: 9359-9368

33 Li J, Kleintschek T, Rieder A, et al. Hydrophobic liquid-infused porous polymer surfaces for antibacterial applications. ACS Appl Mater Interfaces, 2013, 5: 6704-6711

34 Rizzello L, Pompa P P. Nanosilver-based antibacterial drugs and devices: Mechanisms, methodological drawbacks, and guidelines. Chem Soc Rev, 2014, 43: 1501-1518

35 Kummala R, Brobbey K J, Haapanen J, et al. Antibacterial activity of 
silver and titania nanoparticles on glass surfaces. Adv Nat Sci-Nanosci Nanotechnol, 2019, 10: 015012

36 Uhm S H, Lee S B, Song D H, et al. Fabrication of bioactive, antibacterial $\mathrm{TiO}_{2}$ nanotube surfaces, coated with magnetron sputtered $\mathrm{Ag}$ nanostructures for dental applications. J Nanosci Nanotechnol, 2014, 14: 7847-7854

37 Longano D, Ditaranto N, Sabbatini L, et al. Synthesis and antimicrobial activity of copper nanomaterials. In: Cioffi N, Rai M, eds. Nano-Antimicrobials: Progress and Prospects. Berlin: Springer, 2012. $85-117$

38 Grass G, Rensing C, Solioz M. Metallic copper as an antimicrobial surface. Appl Environ Microbiol, 2011, 77: 1541-1547

39 Cometa S, Iatta R, Ricci M A, et al. Analytical characterization and antimicrobial properties of novel copper nanoparticle-loaded electrosynthesized hydrogel coatings. J Bioactive Compatible Polyms, 2013, 28: $508-522$

40 Benetti G, Cavaliere E, Brescia R, et al. Tailored Ag-Cu-Mg multielemental nanoparticles for wide-spectrum antibacterial coating. Nanoscale, 2019, 11: 1626-1635

41 Murata H, Koepsel R R, Matyjaszewski K, et al. Permanent, nonleaching antibacterial surfaces-2: How high density cationic surfaces kill bacterial cells. Biomaterials, 2007, 28: 4870-4879

42 Chen $\mathrm{T}$, Yang $\mathrm{H}, \mathrm{Wu} \mathrm{X}$, et al. Ultrahighly charged amphiphilic polymer brushes with super-antibacterial and self-cleaning capabilities. Langmuir, 2019, 35: 3031-3037

43 Liu L, Peng W, Zhang X, et al. Rational design of phosphonate/ quaternary amine block polymer as an high-efficiency antibacterial coating for metallic substrates. J Mater Sci Tech, 2021, 62: 96-106

44 Román-Kustas J, Hoffman J B, Reed J H, et al. Molecular and topographical organization: Influence on cicada wing wettability and bactericidal properties. Adv Mater Interfaces, 2020, 7: 2000112

45 Pogodin S, Hasan J, Baulin V A, et al. Biophysical model of bacterial cell interactions with nanopatterned cicada wing surfaces. Biophys J, 2013, 104: 835-840

46 Hasan J, Crawford R J, Ivanova E P. Antibacterial surfaces: The quest for a new generation of biomaterials. Trends Biotechnol, 2013, 31: 295-304

47 Xue F, Liu J, Guo L, et al. Theoretical study on the bactericidal nature of nanopatterned surfaces. J Theor Biol, 2015, 385: 1-7

48 Fisher L E, Yang Y, Yuen M F, et al. Bactericidal activity of biomimetic diamond nanocone surfaces. Biointerphases, 2016, 11: 011014

49 May P W, Clegg M, Silva T A, et al. Diamond-coated 'black silicon' as a promising material for high-surface-area electrochemical electrodes and antibacterial surfaces. J Mater Chem B, 2016, 4: $5737-$ 5746

50 Dickson M N, Liang E I, Rodriguez L A, et al. Nanopatterned polymer surfaces with bactericidal properties. Biointerphases, 2015, 10: 021010

51 Ge X, Zhao J, Esmeryan K D, et al. Cicada-inspired fluoridated hydroxyapatite nanostructured surfaces synthesized by electrochemical additive manufacturing. Mater Des, 2020, 193: 108790

52 Ye J, Deng J, Chen Y, et al. Cicada and catkin inspired dual biomimetic antibacterial structure for the surface modification of implant material. Biomater Sci, 2019, 7: 2826-2832

53 Nunamaker D M. Orthopedic implant failure. In: Barber S M, eds. Equine Fracture Repair. 2nd ed. Hoboken: John Wiley \& Sons, 2019

54 Filipović U, Dahmane R G, Ghannouchi S, et al. Bacterial adhesion on orthopedic implants. Adv Colloid Interface Sci, 2020, 283: 102228

55 Hansen L K, Berg K, Johnson D, et al. Efficacy of local rifampin/ minocycline delivery $\left(\mathrm{AIGIS}_{\mathrm{RX}}{ }^{\circledR}\right)$ to eliminate biofilm formation on implanted pacing devices in a rabbit model. Int J Artif Organs, 2010, 33: 627-635

56 Wang Q, Wu L, Liu S, et al. Nanostructured titanium alloys surface modification technology for antibacterial and osteogenic properties. CNANO, 2021, 17: 175-193

57 Zhang Y, Hu K, Xing X, et al. Smart titanium coating composed of antibiotic conjugated peptides as an infection-responsive antibacterial agent. Macromol Biosci, 2021, 21: 2000194

58 Lin X, Yang S, Lai K, et al. Orthopedic implant biomaterials with both osteogenic and anti-infection capacities and associated in vivo evaluation methods. NanoMed-Nanotechnol Biol Med, 2017, 13: 123142

59 Qing Y, Cheng L, Li R, et al. Potential antibacterial mechanism of silver nanoparticles and the optimization of orthopedic implants by advanced modification technologies. Int J Nanomed, 2018, 13: 33113327

60 Wang X, Ning B, Pei X. Tantalum and its derivatives in orthopedic and dental implants: Osteogenesis and antibacterial properties. Colloids Surfs B-Biointerfaces, 2021, 208: 112055

61 Gallardo-Moreno A M, Pacha-Olivenza M A, Saldaña L, et al. In vitro biocompatibility and bacterial adhesion of physico-chemically modified $\mathrm{Ti}_{6} \mathrm{Al}_{4} \mathrm{~V}$ surface by means of $\mathrm{UV}$ irradiation. Acta Biomater, 2009, 5: 181-192

62 Del Curto B, Brunella M F, Giordano C, et al. Decreased bacterial adhesion to surface-treated titanium. Int J Artif Organs, 2005, 28: $718-730$

63 Harris L G, Tosatti S, Wieland M, et al. Staphylococcus aureus adhesion to titanium oxide surfaces coated with non-functionalized and peptide-functionalized poly(1-lysine)-grafted-poly(ethylene glycol) copolymers. Biomaterials, 2004, 25: 4135-4148

64 Han L, Wang Z, Lu X, et al. Mussel-inspired adhesive and transferable free-standing films by self-assembling dexamethasone encapsulated BSA nanoparticles and vancomycin immobilized oxidized alginate. Colloids Surfs B-Biointerfaces, 2015, 126: 452-458

65 Avés E P, Estevez G F, Sader M S, et al. Hydroxyapatite coating by sol-gel on Ti-6Al-4V alloy as drug carrier. J Mater Sci-Mater Med, 2009, 20: 543-547

66 Jiang W, Cipriano A F, Tian $\mathrm{Q}$, et al. In vitro evaluation of $\mathrm{MgSr}$ and $\mathrm{MgCaSr}$ alloys via direct culture with bone marrow derived mesenchymal stem cells. Acta Biomater, 2018, 72: 407-423

67 Pei Y, Zhang G, Zhang C, et al. Corrosion resistance, anticoagulant and antibacterial properties of surface-functionalized magnesium alloys. Mater Lett, 2019, 234: 323-326

68 von Eiff C, Jansen B, Kohnen W, et al. Infections associated with medical devices. Drugs, 2005, 65: 179-214

69 Tambyah P A, Maki D G. Catheter-associated urinary tract infection is rarely symptomatic. Arch Intern Med, 2000, 160: 678-682

70 Rosenthal V D, Bijie H, Maki D G, et al. International nosocomial infection control consortium (INICC) report, data summary of 36 countries, for 2004-2009. Am J Infect Control, 2012, 40: 396-407

71 Zhong Y, Zhou L, Liu X, et al. Incidence, risk factors, and attributable mortality of catheter-related bloodstream infections in the intensive care unit after suspected catheters infection: A retrospective 10-year cohort study. Infect Dis Ther, 2021, 10: 985-999

$72 \mathrm{Su} \mathrm{Y,} \mathrm{Zhi} \mathrm{Z,} \mathrm{Gao} \mathrm{Q,} \mathrm{et} \mathrm{al.} \mathrm{Autoclaving-derived} \mathrm{surface} \mathrm{coating} \mathrm{with} \mathrm{in}$ vitro and in vivo antimicrobial and antibiofilm efficacies. Adv Healthcare Mater, 2017, 6: 1601173

73 Yu H, Liu L, Li X, et al. Fabrication of polylysine based antibacterial coating for catheters by facile electrostatic interaction. Chem Eng J, 2019, 360: 1030-1041

74 Geyer F, D'Acunzi M, Yang C Y, et al. How to coat the inside of narrow and long tubes with a super-liquid-repellent layer: A promising candidate for antibacterial catheters. Adv Mater, 2019, 31: 1801324

75 Liu L, Shi H, Yu H, et al. The recent advances in surface antibacterial strategies for biomedical catheters. Biomater Sci, 2020, 8: 4095-4108

76 Wang Y, Liu S, Ding K, et al. Quaternary tannic acid with improved leachability and biocompatibility for antibacterial medical thermoplastic polyurethane catheters. J Mater Chem B, 2021, 9: 4746-4762

77 Singha P, Locklin J, Handa H. A review of the recent advances in antimicrobial coatings for urinary catheters. Acta Biomater, 2017, 50: $20-40$

78 Wei Q, Becherer T, Angioletti-Uberti S, et al. Protein interactions with polymer coatings and biomaterials. Angew Chem Int Ed, 2014, 53: 8004-8031 
79 Smith R S, Zhang Z, Bouchard M, et al. Vascular catheters with a nonleaching poly-sulfobetaine surface modification reduce thrombus formation and microbial attachment. Sci Transl Med, 2012, 4: 132

80 Francesko A, Fernandes M M, Ivanova K, et al. Bacteria-responsive multilayer coatings comprising polycationic nanospheres for bacteria biofilm prevention on urinary catheters. Acta Biomater, 2016, 33: 203-212

81 Yu H, Liu L, Yang H, et al. Water-insoluble polymeric guanidine derivative and application in the preparation of antibacterial coating of catheter. ACS Appl Mater Interfaces, 2018, 10: 39257-39267

82 Owen L, Laird K. Development of a silver-based dual-function antimicrobial laundry additive and textile coating for the decontamination of healthcare laundry. J Appl Microbiol, 2021, 130: 1012-1022

83 Verma M, Gahlot N, Singh S S J, et al. UV protection and antibacterial treatment of cellulosic fibre (cotton) using chitosan and onion skin dye. Carbohydrate Polyms, 2021, 257: 117612

84 Nam S, Hillyer M B, Condon B D, et al. Silver nanoparticle-infused cotton fiber: Durability and aqueous release of silver in laundry water. J Agric Food Chem, 2020, 68: 13231-13240

85 Tang P, Zhang Z, El-Moghazy A Y, et al. Daylight-induced antibacterial and antiviral cotton cloth for offensive personal protection. ACS Appl Mater Interfaces, 2020, 12: 49442-49451

86 Cuello E A, Mulko L E, Barbero C A, et al. Development of micropatterning polyimide films for enhanced antifouling and antibacterial properties. Colloids Surfs B-Biointerfaces, 2020, 188: 110801

87 Jalil S A, Akram M, Bhat J A, et al. Creating superhydrophobic and antibacterial surfaces on gold by femtosecond laser pulses. Appl Surf Sci, 2020, 506: 144952
88 Zorba V, Stratakis E, Barberoglou M, et al. Biomimetic artificial surfaces quantitatively reproduce the water repellency of a lotus leaf. Adv Mater, 2008, 20: 4049-4054

89 Iwata R, Suk-In P, Hoven V P, et al. Control of nanobiointerfaces generated from well-defined biomimetic polymer brushes for protein and cell manipulations. Biomacromolecules, 2004, 5: 2308-2314

$90 \mathrm{Su}$ X, Yang M, Hao D, et al. Marine antifouling coatings with surface topographies triggered by phase segregation. J Colloid Interface Sci, 2021, 598: 104-112

91 Li G, Cheng G, Xue H, et al. Ultra low fouling zwitterionic polymers with a biomimetic adhesive group. Biomaterials, 2008, 29: 4592-4597

92 Karkhanechi H, Takagi R, Matsuyama H. Enhanced antibiofouling of RO membranes via polydopamine coating and polyzwitterion immobilization. Desalination, 2014, 337: 23-30

93 Yuan S, Luan S, Yan S, et al. Facile fabrication of lubricant-infused wrinkling surface for preventing thrombus formation and infection. ACS Appl Mater Interfaces, 2015, 7: 19466-19473

94 Zhuk I, Jariwala F, Attygalle A B, et al. Self-defensive layer-by-layer films with bacteria-triggered antibiotic release. ACS Nano, 2014, 8: 7733-7745

95 Traba C, Liang J F. Bacteria responsive antibacterial surfaces for indwelling device infections. J Control Release, 2015, 198: 18-25

96 Wei T, Yu Q, Chen H. Responsive and synergistic antibacterial coatings: Fighting against bacteria in a smart and effective way. Adv Healthcare Mater, 2019, 8: 1801381

97 Green D W, Lee K K H, Watson J A, et al. High quality bioreplication of intricate nanostructures from a fragile gecko skin surface with bactericidal properties. Sci Rep, 2017, 7: 41023 